\title{
PROPOSTA DE ASSOCIAÇÃO DE MARCO CONCEITUAL DE ROY COM A TEORIA DA CRISE
}

Margarita Villar Luis *

LUIS, M.V. Proposta de associação de março conceitual de Roy com a teoria da crise. Rev. Esc. Enf. USP, São Paulo, 24(1):11-30, abr. 1990.

Trata-se de um relato sobre os fundamentos da teoria da Crise, propondo sua articulação com o modelo conceitual de Callista ROY ${ }^{18}$. Com objetivo de proporcionar ao enfermeiro um corpo de conhecimentos teórico e instrumental, para assistência a pessoas em crise. Dentro dessa proposta sugere-se ainda, um roteiro de assistência de enfermagem derivado de ambas teorias exemplificado pela autora, através de aplicação prática.

UNITERMOS: Enfermagem psiquiátrica. Intervenf̧ão em crise. Teorias de enfermagem - Callista Roy.

A teoria da crise segundo a literatura especifica, parece ter se originado nos Estados Unidos da América do Norte, na década de quarenta, tendo se desenvolvido na de cinqüenta e atingindo seu auge entre as décadas de sessenta e meados de setenta, durante a política de incentivo à criação e instalação de serviços comunitários (unidades de emergência, ambulatórios e centros de saúde mental), visancio à assistência ao doente mental fora ủo haspital psiquiátrico, além da promoção e manutenção da saúde mental da coinuniciade como um todo 9 . No decorrer desse período e nos anos subseqüentes, o modelo teórico proposto originalmente por CAPLAN 2 , foi questionado em alguns pontos, a serem detalhados na seqüência do trabalho, culminindo com a inclusão de algumas alterações que modificaram bastante sua abordagem.

Na concepção inicial, a teoria da crise constituiu-se num fundamento amplo para uso em atendimento preventivo comunitário e que se pautava numa percepgão centrada em dois niveis; numa visão abrangente dos fatores contínuos ambientais que moldam o desenvolvimento do estilo geral de vida do individun e numa perspectiva circunscrita das crises recorrentes, associadas com mudanças repentinas nas estruturas de conduta do ser humano. Sendo que os dois níveis acentuam mais as influências ambientais do que os fatores de idiossincrasia que determinam as diferenças individuais (CAPLAN ${ }^{2}$ ).

Concomitantemente, foi se desenvolvendo a técnica de intervenção em crise, cujos objetivos tornaram-se a origem das maiores controvérsias.

- Professor Agsistente do Depertamento de Enfermagem Psiquiatrica e Clénclas Humanas da 15scola de Infermagem de RIbelräo Preto-USP. 
$\mathrm{Na}$ concepção de Parad apud MALAN ${ }^{8}$, um indivíduo tendo uma personalidade estável, reage à uma situação de crise sentindo-se oprimido, mas com o tempo pode se adoptar. Para tanto, o objetivo da intervenção em crise é ajuçar o organismo a atingir à adaptação, restituindo-lhe o nível de funcionamento prévio.

Entretanto, BELLAK \& SMALL 1 acrescentam que a dinâmica da reação da crise é muito semelhante à formação de qualquer sintoma provocado pela invasão de um microorganismo patogênico. Nessa situação, o organismo está mais vulnerável e reage quase que automaticamente; no caso da crise com uma sintomatologia neurótica ou psicótica como resposta à situação traumática. Baseando-se nisso, o autor argumenta que visar apenas à manutenção do estado anterior à crise é questionável, pois já que a defesa do organismo é automática, torna-se difícil limitar ou interferir na possibilidade de que o próprio indvíduo, espontaneamente, alcance, inclusive, niveis mais elevados de adaptação. Segundo essa perspectiva, fica evidente que a intervenção em crise deveria se propor a atingir objetivos mais ambiciosos.

Assim, de forma crescente, a intervenção em crise foi enfatizando os aspectos específicos de cada indivíduo e delegando os ambientais a um segundo plano.

Evidenciando essa tendência, outros autores (Sifneos, Morley apud MALAN) 8 argumentam que a intervenção em crise deveria ajudar de forma mais radical pessoas que tivessem potencial para mudar, através do uso do procedimento da interrretação sobre o conflito atual. O que envolve a expectativa de mudanças permanentes no indivíduo, a fim de que possa lidar com esse conflito no futuro, pois somente dessa maneira poderá obter níveis mais elevados de maturidade.

Segundo MALAN 8 , a intervenção que envolve mudanças permanentes no individuo, com a finalidade de lidar com um conflito no futuro só é possivel se o atual estiver relacionado a um conflito básico, cujas origens remontam à infância. Por isso, esse e outros autores BELLAK \& SMALL ${ }^{1}$, JACOBSON ${ }^{5}$ defendem a idéia de que a intervenção em crise está incluída entre as técnicas psicoterápicas breves.

Visualizada como Psicoterapia, a intervenção em crise tem pronto seu instrumento de assistência ao paciente, entretanto para o enfermeiro não especialista em saúde mental e mesmo para o enfermeiro psiquiatra, por não pertencerem à área médica ou da psicologia, ambos não possuem um instrumento adequado que sirva de guia adicional para o seu trabalho. nesse ponto que talvez o modelo conceitual de ROY ${ }^{12}$ possa dar sua contribuição já que, parece que há alguns pontos em comum entre esse modelo e a tecria da crise.

O que se propõe no estudo é uma tentativa de se trabalhar com essas duas fontes de conhecimento associadas, visando proporcionar ao enfermeiro um corpo teórico e instrumental que lhe possibilite atuar com pacientes em crise dentro dos limites impostos pela complexidade da intervenção em crise. 
A teoria da crise fundamenta-se na literatura da psicanálise, tendo recebido também contribuiçōes da sociologia, especialmente da Teoria de Mudanças no papel social.

No início dos anos 40, Lindemann, um dos pioneiros na assistência psiquiátrica em hospital geral (MALAN ${ }^{8}$ ), cristalizou suas idéias sobre a intervenção em situações de crise, através do seu envolvimento clínico num acidente ${ }^{*}$ no qual houve inúmeras vitimas fatais e outras apresentando distúrbios emocionais. A partir dai, dedicou-se aos estudos sobre as reações de Juto c aflição entre os sobreviventes, descrevendo as reações breves e anormalmente prolongadas, manifestadas pelos vários indivíduos envolvidos com a perda de pessoas significativas (LINDEMANN ${ }^{7}$ ).

O autor concluiu que poderia ser útil para a assistência à população desenvolver uma estrutura conceitual de referência construída em torno do conceito de uma crise emocional, a exemplo das reações de luto ocorridas na população anteriormente descrita, uma vez que certos eventos no curso do ciclo de vida de todo individuo podem ser descritos como situações ameaçadoras (LINDEMANN ${ }^{7}$ ).

Posteriormente, em 1946, Lindemann fundou o Wellesley Human Relations Service**, um centro pioneiro de saúde mental comunitária, onde incluiu os serviços de emergência como parte importante da organização. Nesse centro pôde, juntamente com Caplan, dar continuidade às suas proposições teóricas, trabalho esse que culminou no desenvolvimento das técnicas de intervenção em crise (TOPALIS \& AGUILLERA $^{13}$ ).

Caplan com o conhecimento acumulado, fruto de experiências individuais e de trabalhos em conjunto, estabeleceu um modelo conceitual com o intuito de evidenciar suas proposições a respeito dos fatores que interferem e influem na susceptibilidade ao transtorno mental, e as conseqüências disso para a prevenção primária.

O referido modelo é amplo e inicialmente baseia-se na hipótese de que o indivíduo para não sofrer um distúrbio mental, necessita receber continuamente provisões do meio ambiente, adequadas às diversas etapas do desenvolvimento. Essas provisōes classificam-se em físicas, psicossociais e socioculturais ${ }^{2}$, sendo que os três grupos estão totalmente interligados de forma que, qualquer "deficit" ou excesso num deles, causará alteração nos outros. Todavia, CAPLAN ${ }^{2}$, fez a ressalva de que a relação homem-meio ambiente é dialética e, portanto, $o$ individuo não é apenas um agente passivo, mas também pode modificar significativamente o seu meio.

- Incéndio de um clube noturno na cidade americana de Boston-Massachusetts.

* Wellesley Project na área da Universidade de Harvard (ver $A$ Mental Project in a Boston Suburb - in Paul, Benjamin. D., ed., Health Culture and Community. New York, Russel Sage Foundation, 1955, págs. 295-321. 
A essa concepção teórica mais geral, foi associada uma perspectiva mais circunscrita, fundamentada na teoria do desenvolvimento humano de ERIKSON 3. Para quem, o desenvolvimento psicossocial do homem constitui-se de uma seqüência ordenada de oito estágios qualitativamente diferentes entre si, cada um dependendo do outro para um final bem sucedido.

Cada um desses estágios compreende uma fase que envolve tarefas específicas a serem resolvidas, cuja solução encontrada será aplicada nos estágios subseqüentes. Cada uma dessas fases pressupõe mudanças, traduzindo-se num período de transição, caracterizado por condutas mais indefinidas e por transtornos nas áreas intelectual e afetiva (ERIKSON ${ }^{3}$ ). Tais periodos são críticos para o individuo, porque ele se apresenta mais vulnerável em virtude de estar redefinindo a si mesmo e suas relações com os outros (CAPLAN ${ }^{2}$ ).

No que se refere à intervenção na crise, CAPLAN ${ }^{2}$ incluiu a ação dos consultores informais oriundos da comunidade, e os agentes profissionais (médicos, enfermeiras, assistentes sociais). Reconhecendo a importância dos primeiros, considerando-os pessoas-chave da comunidade, por: ser a eles a quem a população de um local recorre, em primeiro lugar, antes de procurar a assistência profissional.

$O$ autor acentuou ainda o fato de que essa influência tanto pode direcionar os indivíduos para soluções adaptativas, como induzi-los à escolha de soluções doentias. Daí a ênfase na sua inclusão em programas preventivos de saúde mental.

No que se refere aos agentes profissionais, o referido autor menciona que a assistência à saúde mental era realizada muito mais em bases do conhecimento informal, inerente à sensibilidade e experiência pessoal de cada um, do que em modelos de atuação pautados em fundamentos básicos de sua profissão. Isso em razão de que a saúde mental era considerada pelas profissões de saúde e de educação como apenas um deciência de seus serviços (CAPLAN ${ }^{2}$ ).

CAPLAN 2 preconizou a necessidade de se entender o conhecimento e a compreensão técnica das formas psicológicas e psiquiátricas de per-ceber, valorizar e manejar os problemas gerados pela crise, às outras profissões de saúde. Contudo, a incorporação dessas formas deveria ser feita de maneira a não modificar a identidade profissional, preservando os objetivos e finalidades específicas que definem a especialidade em si mesma. Assim, ficou a cargo de cada profissão de saúde, encontrar seu modelo formal de intervenção em crise, com ações mais padronizadas e que dessem mais segurança a seus representantes.

Jacobson, fundador do Benjamin Rush Center de Los Angeles, em 1962, parece ter contribuído para realizar essa proposta sugerida, pois o centro proporcionou experiência no atendimento à população e na convivência de equipes multiprofissionais, que através dos registros de suas operaçōes (em 19 meses de atividade) puderam comprovar a eficiência de seus serviços (MALAN ${ }^{8}$ ). 
Esse autor compreende a intervenção em crise em niveis de complexidade, capazes de abranger os agentes informais e os profissionais, desde aqueles de formação geral até as especialistas. Tais niveis foram estabelecidos de acordo com as caracteristicas especificas do gmupo ou do individuo em crise (JACOBSON ${ }^{5}$ ).

Na sequiência serão expostos os conceitos básicos da teoria da crise, separadamente, por questões didáticas; entretanto, devem ser entendidos como atuando de forma interligada.

\section{Crise}

Crise é um fenômeno de tempo limitado, com um resultado que não é pré-determinado no começo. um estado de desequilíbrio psicológico provocado quando a pessoa enfrenta situaçōes que pressupõem ameaça, exigências ou perdas de importantes alvos vitais (CAPLAN ${ }^{2}$ ).

Por muito tempo essa situaçãço é insuperável utilizando-se os mecanismos usuiais de solução de problemas. Durante esse periodo de desorganização, são feitas inúmeras tentativas malogradas visando a solução. Por fim, o individuo elabora uma nova forma de manejar o conflito e eventualmente consegue algum tipo de adaptação que pode ou não ser em seu benefício (CAPLAN ${ }^{2}$, JACOBSON ${ }^{5}$ ).

A resolução da crise depende do reajuste de um complexo de forças conflitivas durante o periodo de desequilibrio, algumas das quais se originam no interior do indivíduo, estando relacionadas com a estrutura da sua personalidade e com a experiência biopsicológica passada. Outras surgem do seu meio ambiente, particularmente da evolução da dificuldade externa (situação enfrentada) e da ajuda ou interferência prejudicial de terceiros (familiares, amigos, conselheiros formais informais) (CAPLAN ${ }^{2}$ ).

ERIKSON ${ }^{3}$ diferenciou esse conceito em dois: as crises evolutivas; periodos de transição ocorridos durante cada estágio do desenvolvimento, e, crises acidentais; períodos semelhantes, só que precipitados por eventos sérios e inevitáveis que surgem de forma abrupta no decorrer da vida.

JACOBSON 5, no entanto, considera a crise como um fenômeno único com início numa época específica. O autor usa um conceito de "crise matriz", definindo-a como um periodo de vários meses e anos, durante os quais o individuo está mais propenso a vivenciar múltiplas tmeaças emocionais e igualmente mais vulnerável às crises. $\mathrm{Na}$ sua visão a crise não é uma conseqüência de uma ameaça específica e descontinua, esta na verdade seria apenas aquela que motiva as pessoas a buscarem ajuda.

O autor referido, vê a necessidade de se entender os eventos antecedentes à crise, como uma série de acontecimentos relacionados, onde o indivíduo foi capaz de lutar isoladamente com cada um deles, exceto com o último por uma razão qualquer, sendo que esse fracasso na luta, no estágio final, tem o efeito de última "gota d'água", que precipita o estado de crise. 
Os exemplos básicos, que ilustram essa perspectiva, são a adolescência e a menopausa, pois os distúrbios observados nesses períodos não são plenamente explicados pelo episódio em si mesmo, devendo ser entendidos também, em termos dos eventos específicos de vida pessoal recentes e suas seqüelas (JACOBSON ${ }^{5}$ ).

Por exemplo, a mulher em fase de menopausa pode vivenciar uma crise devido a estar passando por um período de desentendimentos com seu parceiro, seguida de uma outra adicional, associada ao fato de achar que perdeu a sexualidade por não ter mais capacidade reprodutiva, e, uma possivel terceira crise, se os filhos estiverem saindo de casa para cursarem uma universidade em outro local. Portanto, não basta dizer apenas que a menopausa provoca uma situação de crise, como foi exemplificado, é necessário ter uma compreensão maior dos eventos ameaçadores à saúde mental que ocorrem nesse periodo de vida.

Uma crise simples, terminará de um modo ou de outro num tempo que varia de 04 a 06 semanas, a partir da origem da situação ameaçadora. Entretanto, ela pode se complicar se aparecerem, nesse periodo, múltiplos eventos ameaçadores, sendo às vezes o último deles o resultado mal adaptado com um primeiro risco. Por exemplo, a crise pode começar com uma ameaça de separação conjugal, pode resultar numa separação e esta pode tomar-se, por sua vez, num risco (CAPLAN ${ }^{2}$, JACOBSON ${ }^{5}$ ).

Sintetizando a crise se constitui num ponto crucial na vida do individuo, onde ele tem: a oportunidade de adquirir novos níveis de maturação e reelaborar soluções mal adaptadas, ou o risco de se manifestar um distúrbio psíquico ou psicossomático (JACOBSON ${ }^{5}$ ).

\section{Risco}

Risco é um evento que ameaça um equilíbrio psicológico pré-existente. Ele pode relacionar-se a mudanças no meio ambiente físico (Ex.: um desastre natural) ; na esfera social (Ex.: perda de uma pessoa significativa) ou esfera biológica (Ex.: doença física). Um transtorno psicológico (Ex.: um ataque de ansiedade ou explosão de violência) não se constitui um risco, embora ele possa ser parte de uma crise. O risco pode resultar numa crise, se as mudanças não puderem ser manejadas pelos mecanismos de luta * existentes (JACOBSON ${ }^{5}$ ).

$\mathrm{O}$ evento é percebido como problemático e ameaçador pelo indivíduo dependendo da sua personalidade (maturidade e qualidade da estrutura do Ego) e da experiência pessoal bem sucedida com situações semelhantes (CAPLAN ${ }^{2}$ ).

Dentre os fatores pessonis que interferem para que uma situação seja vista como um risco, desponta o fato de a situação estar relacionada simbolicamente com problemas similares do passado, cuja solução foi inadequada, os quais são revividos nesta situação (CAPLAN ${ }^{2}$, JACOBSON 5 , MALAN ${ }^{\text {) }}$.

- Mecanismos de luta, mecanismos de resolução de problemas e mecanismoz adaptativos foram entendidos como tendo o mesmo sigrificado. 
O meio cultural onde o indiviáuo se desenvolve, através de seus valores, tradições e crenças, também afeta em grande parte a percepção da realidade e as atitudes e aspirações individuais. Quanto mais rica a herança cultural, mais con plexos os problemas que os individuos teräo que aprender a mancjar, mas por outro lado a oportunidade de aquisição de um repertório de habilidades, para resolvê-los, também será maior (CAPLAN ${ }^{2}$ ).

Virtualmente qiıalquer evento pode ser ameaçador, dependendo do seu significado subjetivo para um determinado individuo. Entretanto, em qualquer cultura, alguns eventas de vida têm um maior potencial do que outros para constituírem-se em ameaças. Os especialistas na área têm elaborado listas de tais eventos e a maioria considera como os mais sérios, aqueles que implicam em perda ou separação de entes queridos (cônjuge, criança), morte de membros da família, doença física grave, desemprego, aposentadoria (BELLAK \& SMALL 1, CAPLAN ${ }^{2}$, JACOBSON ${ }^{5}$ ).

Epocas diferentes da vida podem ser significativas em produzir riscos nas pessoas dos dois sexos nas diversas faixas etárias. Tais eventos estão relacionados à emancipação dos adultos jovens, com a separação dos pais, namoro, noivado, casamento, nascimento de filhos. A separação e divórcio são fontes de crise nos adultos dos vinte aos sessenta anos. Sucessos e fracassos profissionais atingem os individuos em qualquer idade e em ambos os sexos. Crises $\mathrm{cm}$ conseqüência de doença ou aposentadoria são mais frequientes na meia idade (CAPLAN ${ }^{2}$, JACOBSON ${ }^{5}$ ).

\section{Comportamento de luta}

Comportamento de luta: significa todo o processo psicológico que serve para manter ou restaurar o equilíbrio psicológico. Ele inclui, mas não se limita aos mecanismos de defesa, pois também se refere aos modelos interpessoais habituais para obter a satisfação das necessidades individuais, tais como dependência de outros para satisfazer suas próprizs exigências emocionais, financeiras ou sexuais (JACOBSON ${ }^{5}$ ).

$O$ equilíbrio do organismo se mantém às custas de mecanismos homeostásicos reequilibradores, de forma que os desvios temporários põem em ação forças opostas que automaticamente procuram restabelecer o organismo. Um risco, em geral, provoca o desencadear de uma variedade de mecanismos de solução de problemas, um dos quais, num certo tempo, resolverá a situação. Caso haja possibilidade de enfrentar esse risco, com mecanismos já utilizados em experiências anteriores, desenvolve-se no individuo a expectativa de resultado favorável e uma maior tolerância à tensão (CAPLAN ${ }^{2}$ ).

Numa crise o estimulo proveniente da situação ameaçadora é maior do que as forças restauradoras comuns, e estas não conseguem atuar no espaço de tempo normal. Isto pode acontecer, porque o indivíduo nunca se deparou com uma situação semelhante e precisa criar novos mecanismos ou re-elaborar os já existentes, adequando-os à realidade atual (CAPLAN ${ }^{2}$ ). 
A segunda suposição torna-se viável, se no passado o indivíduo desenvolveu uma forma de solução de problemas não baseada na realidade, usando mecanismos de defesa irracionais ou comportamento regressivo e alienante, que o levou a atenuar a dificuldade do risco, evitando o seu confronto (CAPLAN ${ }^{2}$, JACOBSON ${ }^{5}$ ).

É importante estar atento à percepção do comportamento de luta da pessoa antes e depois do aparecimento do risco, bem como para as suas flutuações no decorrer da crise e por fim, observar as características desse comportamento após a crise. Com isso, poder-se-á avaliar o grau de adaptação, que os mecanismos de resolução de problemas adquiridos nessa situação, foram capazes de propiciar ao indivíduo (JACOBSON ${ }^{5}$ ).

Portanto, na teoria da crise a luta não encerra em si mesma um juizo de valor, ela não significa um resultado positivo a priori. A luta pode ter como resultado, comportamentos adaptativos ou mal-adaptados. A título de corroborar tal proposição, cita-se o caso de um adolescente com desentendimentos com os pais; ele pode lutar contra o conflito através do abuso de drogas, esse comportamento ao mostrar-se ineficaz pode induzir o jovem a uma segunda tentativa de luta através do suicídio. Outra suposição é que esse mesmo jovem possa alcançar o equilíbrio com um comportamento de luta que busque estabelecer melhores relações parentais, ou com uma separação efetiva deles, com o estabelecimento de relações significativas com outras pessoas (JACOBSON ${ }^{5}$ ).

Assim sendo, a falha nos mecanismos de solução de problemas existentes, frente a um risco, resultará mesmo numa ameaça para o funcionamento prévio do organismo, havendo a possibilidade de aparecerem disfunções psicológicas novas, ou de se acentuarem as já existentes. Porém, o sucesso no domínio desse risco aumentará o repertório de luta do indivíduo, com o acréscimo de mecanismos que o ajudarão em ocasiões futuras (BELLAK \& SMALL ${ }^{1}$, CAPLAN ${ }^{2}$, Sifneos apud MALAN 8).

\section{II - TECNICAS DE INTERVENÇÃO EM CRISE}

A Teoria da Crise preocupa-se com o fenômeno da crise presente, com seus antecedentes imediatos e com seus resultados. A patologia é uma consideração secundária, desde que as crises podem e ocorrem nos chamados individuos sadios. Portanto, é possível se fazer em qualquer paciente um diagnóstico da crise, delineando o equilíbrio pré-existente, um ou mais eventos de risco e o resultado do estado de crise (BELLAK \& SMALL ${ }^{1}$, JACOBSON ${ }^{5}$ ).

O resultado da crise pode variar enormemente em grau de adaptação, estendenảo-se de uma solução do problema orientada na realidade, a uma manifestação psicótica ou neurótica, para a morte através do suicídio, ou à incapacidade de se manter bem fisicamente. Portanto, a natureza determina a crise, a intervenção não pode finalizá-la, mas ela pode alterar seu resultado (CAPLAN ${ }^{2}$, JACOBSON ${ }^{5}$ ). 


\section{- A enfermagem e a Intervenção em crise}

O conteúdo exposto anteriormente dá uma visão do quanto é complexo o fenômeno da crise, portanto, a grande dificuldade é como inserir o enfermeiro na qualidade de interventor no processo da crise, dada a superficialidade da sua formação no que diz respeito ao domínio da área emocional e psiquica do paciente.

Felizmente, a própria teoria da crise dá a resposta, já que por ter se originado de trabalhos de assistência à comunidade, ela previu a intervenção em níveis de complexidade, pois seu objetivo era atingir as pessoas no seu meio antes que elas adoecessem e para tanto necessitou da ajuda das "pessoas-chaves" da comunidade, que seriam os primeiros a "darem o alarme" quando suspeitassem de vulnerabilidade acentuada em algum membro de sua população.

Assim sendo, os niveis mais superficiais de atendimento e que o enfermeiro pode executar, são os seguintes:

\section{$A$ - Tratamento não especifico da crise}

Trata-se do também chamado tratamento de crise "humano" que pode ser levado a cabo por qualquer pessoa apta a estabelecer um relacionamento de apoio, protetor, compassivo, com o individuo em crise podendo evitar que ele se dirija para distorçōes emocionais características de uma crise. Entretanto, essa intervenção deve ser realizada por alguém que tenha a estima desse individuo, mas que não esteja excessivamente identificado com ele. As características psicológicas do interventor devem ser tais que, ele não sinta que sua própria capacidade de tolerar tensões é sobrecarregada pela assimilação do estado de crise do outro. Esse "terapeuta" pode ser um amigo ou membro da família ou alguém colocado numa função de ajuda pela profissão ou acidentalmente, tal como clérigo, médico, juiz, professor, cabeleireira e outros membros da comunidade (JACOBSON ${ }^{5}$, JACOBSON et alii ${ }^{6}$ ).

O instrumento mais importante desse agente informal é ouvir com interesse, sem afastar o emocional do fato, que é uma reação comum da pessoa com estado perturbado pela crise. Além disso, o interventor tem uma atitude de aceitação e dentro de limites encoraja a expressão apropriada de efeitos tais como: pesar, raiva, deixando esse indivíduo "chorar em seus ombros". A seguir, a intervenção deve ser suficientemente objetiva para ajudar a pessoa a clarificar algumas questões envolvidas e ajudá-la a definir o que parece ser uma situação difusa e insuperável. Finalmente, se esse "apoiador" primário julgar que há indicação para uma ajuda mais específica, ele poderá encaminhar o individuo para recursos mais especializados (JACOBSON ${ }^{5}$ ).

A emissão de conselhos específicos só deve ser efetuada quando o interventor fode ver a situação sob o ponto de vista do outro e de uma forma que permita ao indivíduo aceitar ou rejeitar o conselho, com a 
certeza de não perder a ajuda do interventor (JACOBSON ${ }^{5}$, JACOBSON et alii $\left.{ }^{6}\right)$.

\section{$B$ - Tratamento orientado na abordagem geral da crise}

A abordagem geral teve inicio quando LINDEMANN 7 reconheceu que as formas adaptativas de enfrentar o sofrimento devem ser diferenciadas das mal adaptadas.

Esse princípio está baseado no fato de que os padrões de comportamento adaptativos e mal adaptados podem ser identificados e as respostas adaptativas podem ser indicadas. Os mecanismos adaptativos para lidar com situações de vida específicas foram descritos através de estudos de eventos como nascimentos de filhos prematuros, entrada de criança para o jardim de infância, casais em lua de mel e outros (JACOBSON ${ }^{5}$ ).

Um instrumento utilizado na abordagem geral para induzir a respostas adaptativas é a orientação prévia, a qual se constitui numa sessão prática antes do risco principal, familiarizando a pessoa com os eventos pelos quais irá passar. Isso possibilita a investigação, com antecedência, de alternativas possíveis de ação e um certo domínio antecipado sobre o risco, tornando a pessoa menos vulnerável, uma vez que foi submetida a tensão antecipadamente (TOPALIS \& AGUILLERA ${ }^{13}$, JACOBSON et alii ${ }^{6}$ ).

A aboräagem geral não requer um treinamento específico na área de saúde mental, mas requer um conhecimento profundo em espécies particulares de risco e mecanismos de luta usados para lidar com eles. Por exemplo, os enfermeiros de saúde pública e obstétricos são, provavelmente, os mais familiarizados com os padrões de luta relacionados com o nascimento e infância, enquanto os clérigos conhecem melhor os modelos para lidar com o luto. A abordagem geral é um enfoque importante das organizações de auto-ajuda (Ex.: alcoólicos anônimos) (JACOBSON ${ }^{5}$, JACOBSON et alii ${ }^{6}$ ).

A vantagem da abordagem geral é que ela não exige que se lide com uma única característica de cada indivíduo separadamente. Pela sua proposta, todos os individuos que vivenciam um dado risco (aposentadoria, hospitalização, filhos com mal-formações, divórcio, etc.) são assumidos como tendo padrōes de resposta semelhantes. O termo geral reflete a visão de que tais pessoas pertencem a uma "espécie" ou "gênero", sendo possivel então, aplicar essa técnica a uma larga faixa de individuos (JACOBSON 5, JACOBSON et alii ${ }^{6}$ ).

Relembrando as considerações expressas nos conceitos básicos anteriormente expostos, não se admira que JACOBSON 5 faça a ressalva de que essa abordagem tenha algumas limitações, justamente quando se depara com diferenças nas características próprias e culturais do indivíduo. Além de salientar que há alguns riscos sobre os quais não há pesquisa suficiente a respeito dos mecanismos de luta que levariam a resultados adaptativos. 


\section{ASSISTENCIA DE ENFERMAGEM - INTERVENCGAO EM CRISE (MODELO CONCEITUAL DE ROY)}

Acreditando-se que o enfermeiro tenha possibilidade para atuar nesse nivel de intervenção faz-se necessário, agora, um instrumental teórico e prático específico para essa assistência, daí a sugestão de se recorrer ao Modelo Conceitual de ROY ${ }^{12}$, já que, a nosso ver, ele apresenta pontos em comum com a Teoria da Crise.

Numa explanação superficial, o Modelo Conceitual de ROY ${ }^{12}$, refere-se à pessoa como sendo um sistema adaptativo, composto de dois sub-sistemas processadores internos, o Regulador e o Cognator, utilizados pelo indivíduo para se adaptar aos estímulos do ambiente. Compete a esses dispositivos preparar a pessoa para a luta (ataque ou fuga), bem como ffetuar a identificação, acumulação e relação dos estímulos aos quais está submetida (FAWCETT ${ }^{4}$, ROY ${ }^{11}$, MASTAL \& HAMMOND ${ }^{10}$ ) (Vide figura - Ação dos processadores internos do indivíduo).

Os mecanismos referidos são ativados quando uma variação no ambiente (externo ou interno) ${ }^{*}$ acarreta mudanças no grau de satisfação de qualquer necessidade básica; acionando os comportamentos de luta da pessoa os quais se manifestam através de quatro modos adaptativos (o Fisiológico, o Auto-conceito, o Domínio de função e a Interdependência), conforme origem da necessidade que foi afetada (ROY ${ }^{12}$ ).

Do meio ambiente provém os estímulos que causam o desequilibrio no sistema adaptativo (pessoa), o principal estímulo que promove a mudança é denominado Focal, aqueles acessórios que estão presentes na situação constituem o estímulo contextual, e, finalmente, todos os estímulos cujo efeito na situação é incomensurável, estão inclusos no estímulo residual (FAWCETT ${ }^{4}$, MASTAL \& HAMMOND ${ }^{10}$ ).

A este nível já é possível se tentar estabelecer relações entre os conceitos da teoria da crise e do Modelo Conceitual de ROY ${ }^{11}$. Em relação ao conceito de homem não parece haver nenhuma contradição, já que as proposições teóricas de ambos falam em termos de adaptação, quando mencionam comportamentos, modelos, padrões adaptativos e mal adaptados. Evidentemente ROY 11 complementa com maiores dados.

O conceito de homem como sistema adaptativo é reforçado na definição que Caplan e outros fazem sobre o conceito de crise, ao especificá-la como um periodo de desequilibrio momentâneo. também nesse conteúdo e na definição de Risco, que se visualiza implicitamente a existência dos três tipos de estímulos, como fontes geradoras do desequilibrio.

A teoria da crise fala ainda dos mecanismos de luta, como sendo um dos elementos que manejariam as mudanças, evitando o estado de

- Como a autora năo esclareceu suficlentemente esse aspecto para fins práticos, considerar-se-a ambiente externo tudo o que circundar o individuo, e interno tudo aquilo proveniente de dentro da própria pessoa 


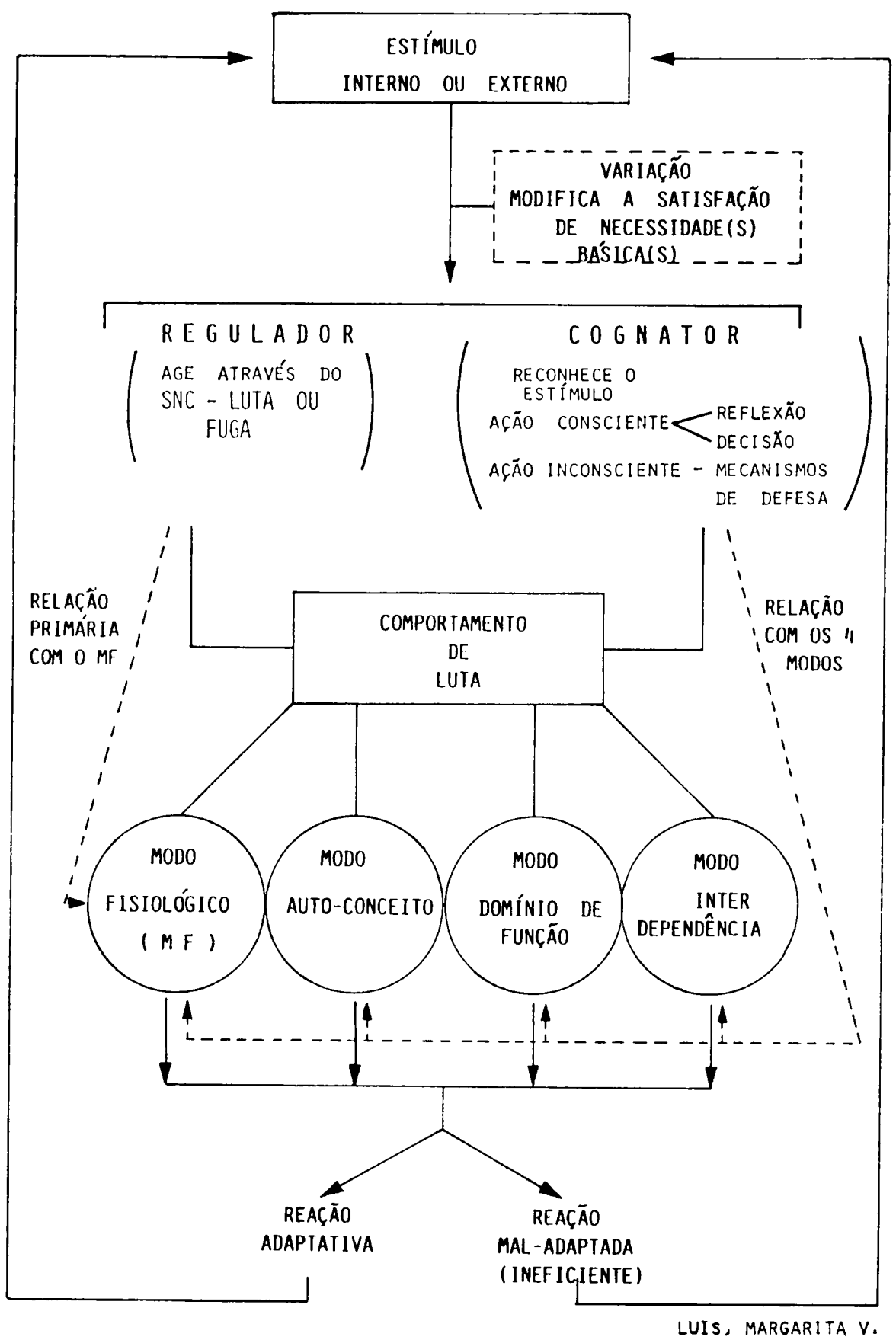


crise quando bem sucedidos. A referida teoria define melhor o chamado comportamento de luta e não lhe atribui qualquer juizo de valor, o que parece ter sido a postura de ROY ${ }^{11,12}$ embora ela não clarifique muito esse aspecto.

Por outro lado, o Modelo Conceitual de ROY 12 contribui especificando mais na estrutura e funcionamento dos mecanismos de luta através da inclusão de componentes como o Regulador e Cognator, cuja atividade se manifestaria através dos modos fisiológico, auto-conceito, domínio de função e interdependência.

Finalmente, segundo ROY 11,12 , a reação proveniente da atividade dos mecanismos resultaria numa reação adaptada ou mal adaptada, tal afirmação também está em consonância com a teoria da crise, a qual refere que a solução de um episódio crítico pode resultar para o indivíduo em padrōes adaptativos ou mal adaptativos. No que diz respeito à ineficiência dos mecanismos em promover a adaptação, os sinais referidos por ROY ${ }^{11}$ podem ser sobrepostos à ansiedade, depressão... próprios do individuo em crise.

Quanto aos comportamentos indicativos de fracasso na adaptação, a mesma analogia pode ser feita, pois a perda da consciência do estado de necessidade, a inabilidade para identificar o objeto meta, para selecionar os meios e o fracasso no alcance desse objeto, podem levar a uma marifiestação neurótica, psicótica, à morte, e a outras soluções mal adaptadas (ROY ${ }^{11}$ ).

A mesma semelhança de pontos de vista é encontrada no que se refere às respostas adaptativas. Para ROY ${ }^{11}$ com elas o indivíduo atinge um nivel mais alto de saúce, para a teoria da crise, ele atinge novos niveis de maturação às custas da aquisição de novo repertório de mecanismos de luta.

ROY ${ }^{11}$ enfatiza a interação do enfermeiro ou de outros com o cliente, como o instrumento primário na manipulação dos elementos desse sistema ou do ambiente. Evidentemente no sentido de conduzir o individuo para soluçōes adaptativas. Da mesma forma, a teoria da crise preconiza uma intervenção que visa a direcionar o indivíduo nesse mesmo sentido.

\section{CONSIDERACOES FINAIS}

$E$ de se esperar que as complicações da associação dos dois modelos ficarão por conta da falta de treino do enfermeiro em fazer anotacões referentes ao paciente no esquema integrado de um processo de assistência de enfermagem. Pois, o que se vê geralmente são anotaçōes de enfermagem isoladas e que em sua maioria se limitam a relatar a assistência de algumas necessidades físicas, no controle de sinais vitais o ministração de medicamentos.

Certamente isso torna o modelo corceitual de ROY 11,12 bastante complexo, sendo a sua aplicação na integra inacessivel à maioria dos 
enfermeiros. Por isso, este trabalho além de visar à associação desse modelo conceitual com outra Teoria que o complementasse, também se preocupou em tornar seu processo de enfermagem mais viável para a nossa prática.

A proposta sugerida trata-se de uma variação do processo, mais simplificada que se constitui numa etapa inicial cujo objetivo é treinar o pensamento do enfermeiro a refletir "o que" está fazendo, "para que" e "qual" será o próximo passo dentro de um determinado referencial teórico.

O instrumento proposto denomina-se "Roteiro para assistência de enfermagem em crise" (Anexo), e pode ser aplicado a todos os individuos que vivenciarem situaçôes consideradas de crise. Inicialmente ele contém um espaço para identificação e caracterização geral do paciente. A segunda etapa, a Evolução de Enfermagem, inclui cinco divisões: relato do comportamento, descrição do risco, impressões do enfermeiro, intervenção e avaliação.

1. Relato do comportamento: Trata-se de uma descrição das ações, reações, sintomas objetivos e o relato dos dados subjetivos obtidos através de observação e de entrevistas.

2. Descrição dos riscos: Procura-se identificar os fatores que desencadearam ou influenciaram o aparecimento dos comportamentos recentes. Isso inclui estabelecer as prioridades, levando-se em conta os critérios de ameaça à vita, ao desenvolvimento, à integridade do indivíduo, família e comunidade.

3. Impressões do Enfermeiro: Supõe-se o levantamento de hipóteses a partir da observação e comunicação do paciente em cada entrevista ou procedimento executado. A partir dai identificam-se os problemas e estabelecem-se as metas as quais pressupöem a mudança que se espera obter no comportamento do paciente, visardo uma melhor adaptação ao episódio vivenciado.

4. Intervenção: Inclui as orientações, classificaçōes, seleção de ten-tativas junto com o paciente, que visem mudança em direção a um comportamento mais adaptado (mais construtivo e integrador) ou que, no mínimo, mantenham a estabilidade de comportamentos adaptativos, anterior ao distúrbio recente.

5. Avaliação:Pretende-se avaliar a eficácia da intervenção de enfermagem a partir do resultado próximo àquele que o enfermeiro havia considerado previamente como meta a ser alcançada em termos de niveis de adaptação ao episódio ocorrido.

Espera-se que o uso desse roteiro sirva como um exercicio que contribua para que o enfermeiro sinta-se mais preparado para utilizar na integra o modelo conceitual de Roy. Como uma contribuição apresenta-se, em anexo, um estudo de caso onde se aplicou o roteiro suge- 
rido. A paciente em questão é uma mulher grávida, atendida num centro de saúde, onde estava freqüentando um grupo de orientação à gravidez.

Durante sua assistência foram efetuadas cinco intervenções no grupo e além dessas, após o término com o grupo, a paciente foi entrevistada individualmente por três vezes (na primeira, segunda e quinta intervenções).

LUIS, M.V. Proposal to association of the Roy conceptual model with the crisis theory. Rev. Esc. Enf. USP, São Paulo, 24(1):11-30, Apr. 1990.

It is reported the crisis theory framework's and is proposed its linkage with the Callista Roy conceptual Model. The aim is to provide the nurse with an instrumental and theoritical framework of the knowledge of the person in crisis intervention. In this proposition is still suggested, a guide to nursing care. It is derived of both teories and exemplified by the author trough practice application.

UNITERMS: Psychiatric nursing. Crisis intervention. Nursing teory-Callista Roy.

\section{REFERENCIAS BIBLIOGRAFICAS}

1. BELLAK, L.M.D. \& SMALL, L. Psicoterapia de emergência \& psicoterapia breve. Porto Alegre, Artes Médicas, 1980.

2. CAPLAN, G. Psicoterapia preventiva. Buenos Aires, Paidó, 1950.

3. ERIKSON, E.H. Infância y sociedade. 2. ed. Buenos Aires, Hormé, 1966.

4. FAWCETT, J. Analysis and ovaluation of conceptual models of nursing. Philadelphia, Davis, 1984.

5. JACOBSON, G.G. Crises: oriented therapy. Psychiatr. Clin. North Am., Philadelphia, 2(1):39-53, Apr. 1979.

6. JACOBSON, G.F. et alli. Generic and individual approacises to crises intervention. Am. J. Public. Health, Washington, 58(2):338-42, Feb. 1968.

7. LINDEMANN, E. Sintomatology and management of acuie grief. Amer. J. Psychiat., Hanover, 101(8):141-8, Sept. 1944.

8. MALAN, D As fronteiras da psicoterapia breve. Porto Alegre, Artes Médicas, 1981.

9. MARTINS, C. Psiquiatria: ascensão, queda e resgate. In: KNOBEL, M. \& SAIDEMBERG, S. Psiquiatria e saúde mental. São Paulo, Autores Associados, 1983. Cap. 1. p. 51-6.

10. MASTAL, M.F. \& HAMMOND, H. Analyses and expansion of the Roy adaptation model: a contribution to holistic nursing. ANS, Germintow, 2(4):71-81, July 1980.

11. ROY, S.C. Adaptation: a conceptual framework for nursing practice. 2. ed. New York, Appleton-Century Crofts, 1980.

12. Introduction to nursing and adaptation model. Englewood Cliffs, Prentice-Hall, 1976.

13. TOPalis, M. \& AGUILLera, D.C. Psychiatric nursing. Saint Louis, Mosby, 1978. 


\section{ANEXO}

\section{ROTEIRO PARA ASSISTENCIA DE ENFERMAGEM A PACIENTES EM CRISE}

Atendimento: Hospitalar ( ) Clínica

C.S.

Ano: 1987 Comunidace (X).

(dita)

(C.S., Ambulatório)

A.P.

Idede:

34 anos

FEXM.

Nome:

(iniciais)

Casada

Estado Civil:

Filhos :

Outras Obs.:

Grávida $/ 4 \mathrm{~m}$

Procedência:

Ribeirão Preto

EVOLUÇAO DE ENFTRMAGEM

\section{I - RELATO DO COMPORTAMENTO}

1* entrevista

- Após as atividades de grupo busca seguicamente o esclarecimento de suas dúvidas

- Tem bronquite asmática que piora durante algumas noites.

- Tem preferência por atendimentos rápidos, em corredores, onde outras pessoas a vêm de longe. Não aceitou atendinıento individual.

\section{2.* entrevista}

- Aparenta aflição, mostra-se um pouco dispréeica e com respiração sibilante.

- Mostra-so ansiosa devido às crises de tosse que vem apresentando e com a toxicidade do medicamento.

- O marido está muito aflito com a coença dela e suas atituces (preocupacão excessiva, vigilancia, choro) a deixam mais nervosa.

$3^{4}$ entrevista

- Teve um acesso de bronquite como este há 2 anos atrás ao cuidar da mãe durante os meses em que ficou hospitalizada, apos os quais veio a faleccr.

- Associa esse episódio de doença com os cuidacos à mão, pois saia do «quente» (quarto para o «frio» (rua). Depois deuns meses «sarou».

- Os acessos de bronquite voltaram na gravidez atual.

- Ja no segundo filho o marido não queria que ela engravidasse, atualmente ambos não queriam a gravidez. A última gravidez foi há 6 anos. 
- Demonstra preocupação em que este episódio de bronquite não passe mais. 4. entrevista

- «A» está aceitando que realmente está insegura e com mecio desta gravidez e da vinda do bebê.

- Começa a associar as crises de bronquite com o nervosismo.

- Não demonstra tanta ansieciade durante a entrevista individual e no grupo, nem se apresentts mais com dificuldade respiratóra.

5." entrevista

- Sentese bem melhor a acha que vai ser capaz de enfrentar a situaçăo, despediuse, pois acha que não precisará vir mais.

- Relata que precisa aproveitar o tempo que sobra para acabar o enxoval, e demais preparativos para 0 bebe.

- Refere que se tiver outras dúvidas ou algum problaina voltará a nos procurar.

\section{II - DESORICAO DOS RISCOS}

1. entrevista

- A paciente tem maior sensibilidade nos brónquios.

\section{2.* entrevista}

- Desconhecimento no tocante ao uso de dosagem de medicação anti-alérgica.

3* entrevista

- Conflito emocional potencializando o problema organico.

- «A» é mais velha que a maioria das participantes do grupo.

- Gravidez rejeitada no início pelo casal.

- Intervalo grande entre a última gravidez e a atual.

\section{II - IMPRESSOES DO ENFERMEIRO}

\section{a - Problemas}

1* entrevista

- Tem dificuldade para se expor em grupo.

- «A» nāo aceita seguimento individual..

\section{2." entrevista}

- «A» não sabe usar corretamante o medicamento prescrito pelo médico. 
- O marido sente-se impotente (e talvez culpacio pela gravidez) durante as crises de bronquite de «A».

$3^{*}$ entrevista

- A somatização é a forma utilizada por «A» para lidar com situações de tensão.

- Por scr mais velha que a maioria das participantes, sente-se na obrigação do parecer mals experiente. (Por isso não aceitou o seguimento individual).

- Tem medo desta gravidez por ser uma situação «nova», que está modificando a dinâmica familiar (as outras crianças têm 7 e 8 anos). « como se fosse a primeira vez».

— «A» não tem um entendimento claro da situação, não percebe $\theta$ não aceita a hipotese de que está insegura e com meảo. Ela canaliza toca a emoção e dúvidas para a área física.

\section{b - Metas}

2. entrevista

- «A» estará ciente do uso aciequado e dos efeitos colaterais do medicamento prescrito.

- Tornar a perticipação do marido eficaz, de maneira a diminuir os sentitmentos de inpotência.

- Aliviar o desconforto respiratório de «A».

3* entrevista

- Ajudar «A» a entender que não expressar as emogões está influenciando negativamente sua função respiratória.

4* entrevista

- Tornar compreensível para «A» que a insegurança, a rejeiçăo, o medo săo sentimentos frequientes, quando se vivencia uma situação desconhecida ou que vai alterar a dinâmica de vida da pessos.

5. entrevista

- Demonstrar disponibilidade para contatos em outras oportunidades, caso «A» julgue ser necessário.

\section{IV - INERVENGAO}

2. entrevista

- Dar informaçóes corretas a respeito do uso dos medicamentos antialérgicos e antinflamatórios. 
- Sugerir a vaporização do quarto (com panela e folhas de eucalipto) durante as crises de tosse a fim de umedecer o ambiente.

- Sugerir que o marido se responsabilize em providenciar gravetos e folhas de eucalipto para a vaporizaçũo.

2* entrevista (grupo)

- Abordar no grupo o tema: expressão de emoçðes através da manifestação de órgãos ou tecidos. Incentivar a exposição de experiências do tipo, pelos participantes.

32 entrevista

- Incentivar no grupo a exprescão dos sentimentos que cada um dos participantes teve ao sabcr que estava grávida. Explorar o sentimento de rejeição da gravidez entre as participantes (inclusive «A») e as causas que alegaram para tal. Ressaltar os pontos em comum.

4. entrevista

- Colocar para discutir no grupo as alteraçðes que a vinda de um bebê provoca no meio familiar. Solicitar experiéncias dos participantes (inclusive de $\langle A \gg$ ).

- Estimular no grupo o aparecimento de sugestós que mostrem alternativas para a melhor aceitação do bebê pelos irmãos.

$5^{*}$ entrevista

- Ir.centivar a colaboração entre vizinhos próximos.

- Orientar todos os participantes para que busquem ajuda e informações quando sentirem necessidađe (orientar «A» individualmente, reforçando o exposto, após o grupo).

\section{v - AVArIAĢa}

- «A» está ciente das indicaçóes e contraindicações de seus medicamentos, está usando-os menos e com mais critério.

- Informa que está fazendo a vaporização do quarto ao deitar e está sentindo que lho faz bem.

- o marido está mais tranquiilo, sente-se mais útil, pois para buscar os eucaliptos precisa andar $1 \mathrm{~km}$ de bicicleta e com isso sente que participa ativamente do tratamento.

- Apesar de não ter aceitado uma entrevista individual formal, ela tem se beneficiado das reunioas em grupo, tem assistico todas e relata que «a gente sempre aproveita alguma coisa». 
- «A» verbalizou que sentia muito medo de ficar sozinha durante a gravidez do segundo filho e que nesta, algumas vezes, também sente, pois o marido trabalha à noite.

- Concorda que um bcbe depois de tanto tempo a preocupa, pois «sente-se como da primeira vez», «já não lembra como era», já «esqueceu de lidar com bebê novos.

- Percebeu que sempre que fica nervosa suas crises pioram (o entendimento de que somatiza suas emoç̋es é uma meta que só será alcançada a longo prazo e com tratamento mais especializado).

- No momento pareco ter restabelecido seu equilíbrio ao nível anterior à gravidez.

- O fato da enfermeira não ter obrigacio «A» a se sujeitar a um seguimento individual, procurando adaptar o atendimento à sua problemática, encorajou «A» a continuar vindo e estabeleceu o clima de confiança que propiciou sua melhora.

Recebido em 18/08/88 